\title{
Interaction of $\mathrm{HNCO}$ with $\mathrm{Au}(111)$ surfaces
}

\author{
A.P. Farkas, A. Berkó, F. Solymosi * \\ Reaction Kinetics Research Group, University of Szeged, P.O.Box 168, H-6701 Szeged, Hungary
}

\section{A R T I C L E I N F O}

\section{Article history:}

Received 22 February 2012

Accepted 25 April 2012

Available online 5 May 2012

\section{Keywords:}

HNCO

Au(111) surface

NCO surface species

$\mathrm{NO}+\mathrm{CO}$ reaction

HREEL spectroscopy

\begin{abstract}
A B S T R A C T
The surface chemistry of isocyanic acid, $\mathrm{HNCO}$, and its dissociation product, NCO, was studied on clean, Odosed and $\mathrm{Ar}$ ion bombarded $\mathrm{Au}(111)$ surfaces. The techniques used are high resolution energy loss spectroscopy (HREELS) and temperature-programmed desorption (TPD). The structure of Ar ion etched surface is explored by scanning tunneling microscopy (STM). HNCO adsorbs molecularly on Au(111) surface at $100 \mathrm{~K}$ yielding strong losses at 1390,2270 and $3230 \mathrm{~cm}^{-1}$. The weakly adsorbed HNCO desorbs in two peaks characterized by $T_{p}=130$ and $145 \mathrm{~K}$. The dissociation of the chemisorbed $\mathrm{HNCO}$ occurs at $150 \mathrm{~K}$ to give NCO species characterized by a vibration at $2185 \mathrm{~cm}^{-1}$. The dissociation process is facilitated by the presence of preadsorbed $\mathrm{O}$ and by defect sites on $\mathrm{Au}(111)$ produced by $\mathrm{Ar}$ ion bombardment. In the latter case the loss feature of $\mathrm{NCO}$ appeared at $2130 \mathrm{~cm}^{-1}$. Isocyanate on $\mathrm{Au}(111)$ surface was found to be more stable than on the single crystal surfaces of Pt-group metals. Results are compared with those obtained on supported Au catalysts.
\end{abstract}

(C) 2012 Elsevier B.V. All rights reserved.

\section{Introduction}

Since the discovery and subsequent studies of the formation of NCO surface complex during the catalytic reaction of $\mathrm{NO}+\mathrm{CO}$ on supported Pt metals [1-8], a huge amount of work has been published on its chemistry. Despite the extensive studies, there is still a controversy concerning the location and the role of NCO formed in the catalytic reduction of NO with $\mathrm{CO}$ and with hydrocarbons. The use of $\mathrm{HNCO}$ as a source of NCO species, however, provided an excellent possibility to produce NCO in high concentration on the surfaces of solids even at low temperature and to establish its bonding, stability and reactions. The most important findings are as follows: (i) NCO surface species developed in the catalytic reduction of NO is formed on the metals, but after its formation it migrates onto the supports, where it is stabilized [9-13]. This spillover process was first clearly demonstrated in the case of $\mathrm{Rh} / \mathrm{SiO}_{2}$ [12], (ii) the position of the absorption band of NCO species in the IR spectra varies with the nature of oxidic supports $\left(\mathrm{Al}_{2} \mathrm{O}_{3}, \mathrm{MgO}\right.$, $\left.\mathrm{TiO}_{2}, \mathrm{CeO}_{2}, \mathrm{ZSM}-5\right)$ and fell in the range of $2210-2315 \mathrm{~cm}^{-1}$ [7-10], (iii) as was revealed by the studies performed on metal single crystals in UHV, the characteristic vibration of NCO bonded to the metals is at $2170-2190 \mathrm{~cm}^{-1}$, which is almost independent of the nature of the metals [14-26], (iv) in contrast to the NCO attached to the oxides, isocyanate on the metals is a rather unstable species, and decomposes completely around 300-330 K [14-26]. Theoretical calculation using the density functional formalism (DFT) disclosed more details on the adsorbate-substrate interaction on different sites of metals and greatly

\footnotetext{
* Corresponding author. Fax: + 3662544106.

E-mail address: fsolym@chem.u-szeged.hu (F. Solymosi).
}

contributed to the better understanding of the chemistry of NCO on catalyst surfaces [27-30].

Recently it was reported that not only the Pt metals are active for NO destruction, but Au nanoparticles on titania also catalyze the $\mathrm{NO}+\mathrm{CO}$ reaction even at lower temperatures [31]. Initial FTIR studies failed to identify the formation of NCO [32,33], which led to a proposal of a different reaction mechanism compared to that occurring on Pt metals. More extensive studies, however, disclosed that NCO surface complex does form on supported Au catalyst in the high temperature reduction of NO with $\mathrm{CO}[34,35]$.

The primary aim of the present study is to produce NCO species on $\mathrm{Au}(111)$ surface free of support by the dissociation of HNCO and establish its chemistry. Besides the clean $\mathrm{Au}(111)$, the interaction of HNCO will be examined with ion bombarded and oxygen-dosed $\mathrm{Au}(111)$ surfaces. It is known that low energy ion bombardment generates significant structural alterations ranging from adatoms to vacancies, which lead to the increased reactivity of the surface [36-41]. On the other hand adsorbed $\mathrm{O}$ adatoms on $\mathrm{Au}(111)$ can also enhance its reactivity towards chemisorption of different molecules [42-44].

\section{Experimental}

The $\mathrm{Au}(111)$ crystal used in this work was a product of MaTeck $\mathrm{GmbH}$, purity $99.999 \%$. It was secured to a Mo plate, which was connected via a copper block directly to a liquid nitrogen reservoir. Initially the sample was cleaned by repeated cycles of $\mathrm{Ar}^{+}$sputtering (typically $2 \mathrm{kV}, 1 \times 10^{-7}$ mbar Ar, $300 \mathrm{~K}, 10 \mu \mathrm{A}$ for $10-30 \mathrm{~min}$ ) and annealing to $850-1000 \mathrm{~K}$ until no contaminations were detected by AES. The sample was heated with a tungsten filament situated at the back of the sample from 100 to $900-1000 \mathrm{~K}$. Its temperature was 
monitored by a chromel-alumel thermocouple pressed into a hole drilled into the side of a crystal and was controlled with a feedback circuit to provide a linear heating rate of ca. $2 \mathrm{~K} / \mathrm{s}$. Gases were dosed through a $0.1 \mathrm{~mm}$ diameter capillary that terminated $2 \mathrm{~cm}$ from the sample. The local pressure at the sample was about $10^{-7}$ mbar during dosing. The dosing temperature was $\sim 95-100 \mathrm{~K}$ unless otherwise noted.

In the preparation of ion bombarded surface we followed the method described before [36,37]. The cleaned $\mathrm{Au}(111)$ surface was etched for 10 min with $2 \mathrm{keV} \mathrm{Ar}{ }^{+}$ions either at room temperature and/or after cooling to $\sim 100 \mathrm{~K}$. The angle of incidence of the $\mathrm{Ar}^{+}$ions was $45^{\circ}$, and the ion gun delivered a current density of $10 \mu \mathrm{A} / \mathrm{cm}^{2}$. Oxygen deposition was carried out by the method described by Friend et al. [42]. Au sample was exposed to $\mathrm{NO}_{2}$ at $100 \mathrm{~K}$ for $1-5 \mathrm{~min}$, which resulted in a multilayer $\mathrm{NO}_{2}$. Afterwards the sample was biased to $+100 \mathrm{~V}$ and exposed to an electron source of the mass spectrometer filament with an emission current of $2 \mathrm{~mA}$ for $1 \mathrm{~min}$. Upon heating the adsorbed layer to $300 \mathrm{~K}$ the weakly adsorbed $\mathrm{NO}_{2}$ desorbed and the adsorbed oxygen atoms remained on the surface. Repeating this procedure several times the surface concentration of adsorbed 0 atoms can be increased. As was reported by Friend et al. [42] oxygen desorbed from $\mathrm{Au}(111)$ with a $\mathrm{T}_{\mathrm{p}}=550 \mathrm{~K}$, the amount of $\mathrm{O}_{2}$ desorbed allows to determine the approximate coverage of adsorbed $\mathrm{O}$. The preparation of HNCO was described in our previous papers in detail [9].

The experimental work was performed in a two-level UHV chamber with a routine base pressure of $5 \times 10^{-10}$ mbar produced by turbomolecular pump. The chamber was equipped with facilities for AES, HREELS and TPD. The HREEL spectrometer (LK, ELS 3000) is situated in the lower level of the chamber and has a resolution of $20-40 \mathrm{~cm}^{-1}$ (FWHM). The count rates in the elastic peak were typically in the range of $1 \times 10^{4}$ to $1 \times 10^{5}$ counts-per-second (cps). All spectra reported were recorded with primary beam energy of $6.5 \mathrm{eV}$ and at an incident angle of $60^{\circ}$ with respect to the surface normal in the specular direction.

An ultrahigh vacuum compatible, room temperature scanning tunneling microscope (WA Technology, U.K.) was used for the study of the nanoscale morphological changes of $\mathrm{Au}(111)$ surface induced by $\mathrm{Ar}^{+}$bombardment. It was installed in a separate UHV chamber capable also for Auger-electron spectroscopy (AES). The latter technique was substantially important to check the cleanliness of the probe, although, the appearance of the characteristic "herringbone" decoration of the large (111) terraces indicated also clearly the purity of the gold surface [41]. The STM images were taken in the so called constant current mode with an electrochemically etched tungsten tip. For the calibration of the STM head, a routinely examined rutile $\mathrm{TiO}_{2}(110)$ surface served. The STM images of $256 \times 256$ pixels were typically recorded at a bias of $+1 \mathrm{~V}$ on the sample and an average tunneling current of approximately $10 \mathrm{nA}$. The recorded images were analyzed with commercial SPIP image processor software.

\section{Results and discussion}

\subsection{Clean $A u(111)$ surface}

HREELS spectra of $\mathrm{Au}(111)$ at different HNCO exposures at $~ 100 \mathrm{~K}$ are presented in Fig. 1A. The adsorption of HNCO caused the appearance of several losses at 515, 900, 990, 1390, 2270, 2780 and $3230 \mathrm{~cm}^{-1}$, which became more intense with the increase of the HNCO exposure. The most important spectral feature is the loss at the $2270 \mathrm{~cm}^{-1}$, which is due to the asymmetric stretching of molecularly adsorbed HNCO. The position of this loss was found to be independent of the surface coverage of adsorbed HNCO. The same feature was observed in the HREEL spectra of HNCO adsorbed on $\mathrm{Pt}(111)$ [14] and $\mathrm{Rh}(111)$ [45], whereas the RAIRS disclosed a coverage dependence on Pt(111) surface [25]. The symmetric stretch, which is much weaker than the previous one, can be detected at
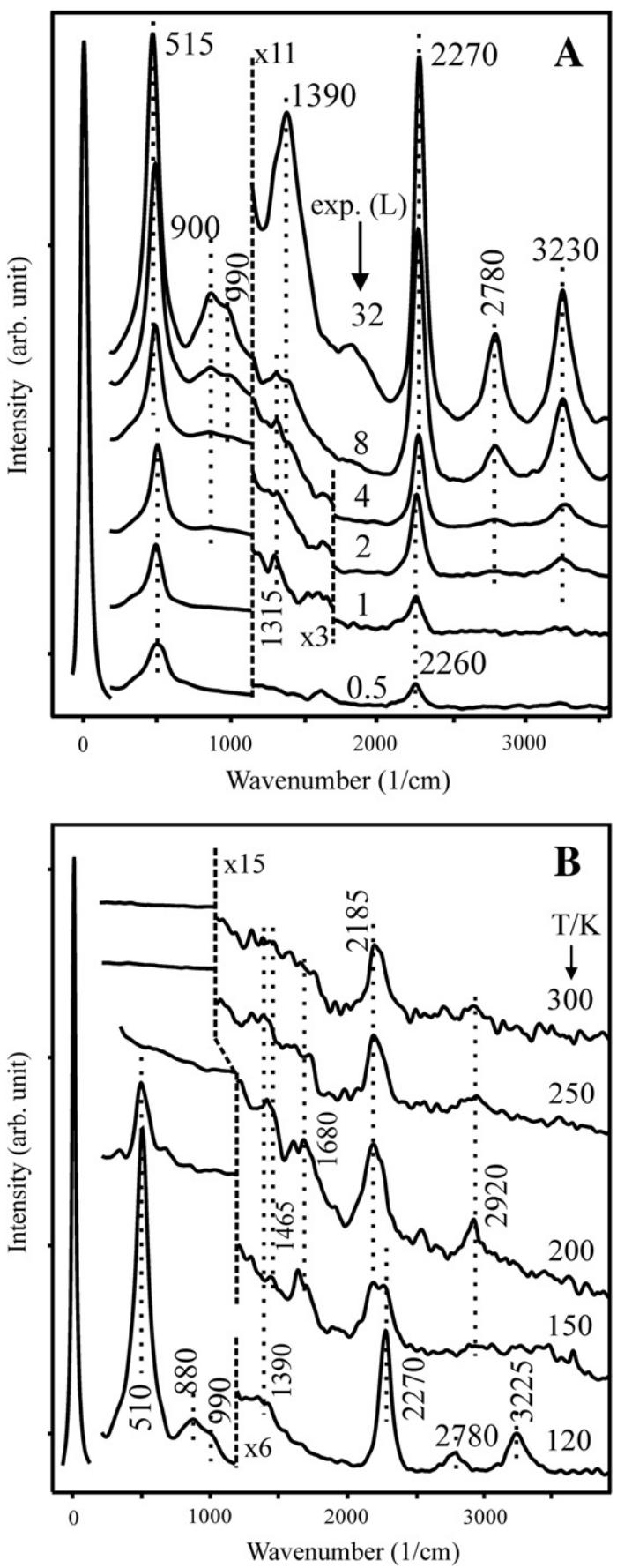

Fig. 1. Effects of HNCO exposure on the HREEL spectra of untreated $\mathrm{Au}(111)$ at $\sim 100 \mathrm{~K}$ (A), and subsequent annealing (B) (exposure of HNCO was $8.0 \mathrm{~L}$ ).

$1390 \mathrm{~cm}^{-1}$. The peak at $3230 \mathrm{~cm}^{-1}$ is the NH stretching. We assume that the loss at $2920 \mathrm{~cm}^{-1}$ and that at $2780 \mathrm{~cm}^{-1}$ are the overtones of the peaks at $1465 \mathrm{~cm}^{-1}$ and at $1390 \mathrm{~cm}^{-1}$ [46]. The vibration at $1615-1620 \mathrm{~cm}^{-1}$, which appears sometimes, is very likely the result of the adsorption of $\mathrm{H}_{2} \mathrm{O}$ from the background. The positions of the vibration losses observed and their possible assignment are presented in Table 1, which also contains the results obtained for other metal surfaces.

Annealing the adsorbed layer resulted in attenuation of vibration loss at $2270 \mathrm{~cm}^{-1}$, and in the development of new spectral feature at $2185 \mathrm{~cm}^{-1}$ at around $150 \mathrm{~K}$ (Fig. 1B). This vibration loss was detectable up to $\sim 430 \mathrm{~K}$. The loss at $2170-2185 \mathrm{~cm}^{-1}$ was also 
Table 1

Frequencies $\left(\mathrm{cm}^{-1}\right)$ and assignment of the fundamental vibrations of vapor, solid and adsorbed HNCO.

\begin{tabular}{llllll}
\hline Assignment & Vapor & Solid & $\operatorname{Pt}(111)[14]$ & $\mathrm{Rh}(111)[15]$ & $\begin{array}{l}\mathrm{Au}(111) \\
\text { [present study] }\end{array}$ \\
\hline$v_{1}\left(\mathrm{a}^{\prime}\right) v(\mathrm{NH})$ & 3531 & 3133 & 3240 & $3373 ; 3240$ & 3230 \\
$2 v_{3}$ & & & & & 2780 \\
$v_{2}\left(\mathrm{a}^{\prime}\right) v_{\mathrm{a}}(\mathrm{NCO})$ & 2274 & 2246 & 2270 & 2277 & 2270 \\
$v_{4}+v_{6}$ & 1480 & 1460 & 1450 & 1444 & \\
$v_{4}+v_{5}$ & 1371 & 1377 & & 1419 & \\
$v_{3}\left(\mathrm{a}^{\prime}\right) v_{\mathrm{s}}(\mathrm{NCO})$ & 1327 & 1326 & 1360 & 1322 & 1390 \\
$v_{4}\left(\mathrm{a}^{\prime}\right) \delta(\mathrm{NCO})$ & 797 & - & 870 & & 900 \\
$v_{5}\left(\mathrm{a}^{\prime}\right)$ hindered & 572 & - & 530 & & 515 \\
$\quad$ rotation & & & & & \\
$v_{6}\left(\mathrm{a}^{\prime \prime}\right)$ & 670 & - & & &
\end{tabular}

Note. Data for HNCO in vapor and solid phases were taken from Ref. [15] $v_{4}+v_{6} ; v_{4}+v_{5}$ correspond to the combination of fundamental vibrations.

observed by different vibration spectroscopic studies on other metal single crystal surfaces, and was attributed to the asymmetric stretching of surface NCO species [14-24]. Accordingly adsorbed HNCO undergoes dissociation on $\mathrm{Au}(111)$ surface around $150 \mathrm{~K}$, practically at the same temperature as the desorption of HNCO (Fig. 2A),

$\mathrm{HNCO}_{(\mathrm{a})}=\mathrm{NCO}_{(\mathrm{a})}+\mathrm{H}_{(\mathrm{a})}$

although this reaction was not expected to occur on the relatively inert $\mathrm{Au}(111)$. The disappearance of the $\mathrm{N}-\mathrm{H}$ stretching and the attenuation of the 510 and $2780 \mathrm{~cm}^{-1}$ vibrations characteristic also to molecular HNCO, is in good harmony with the occurring of the dissociation process. This reaction proceeded easily on Pt metals [14-25], but on $\mathrm{Cu}(111)$ it required the presence of preadsorbed $\mathrm{O}$ atoms [45]. However, we cannot exclude the possibility that the method (EEL spectroscopy in the electronic range), applied earlier in the case of $\mathrm{Cu}(111)$ was much less sensitive than the HREEL spectroscopy used at the present.

TPD spectra following the HNCO adsorption on $\mathrm{Au}(111)$ at different exposures are displayed in Fig. 2A. At lower exposure, up to 1.0 L HNCO desorbs with a peak, $T_{p}=145 \mathrm{~K}$. No alteration occurs in this value with the increase of the exposure, which suggests a first order desorption. The activation energy of this process calculated from the peak temperature is $36 \mathrm{~kJ} / \mathrm{mol}$. The activation energy for desorption processes was calculated using the Redhead formula. Above $1.0 \mathrm{~L}$ exposure another peak is developed with $\mathrm{T}_{\mathrm{p}}=130 \mathrm{~K}$, which cannot be saturated. We attribute this peak to the desorption of a condensed layer. We obtained $32 \mathrm{~kJ} / \mathrm{mol}$ for the activation energy of this process. At higher
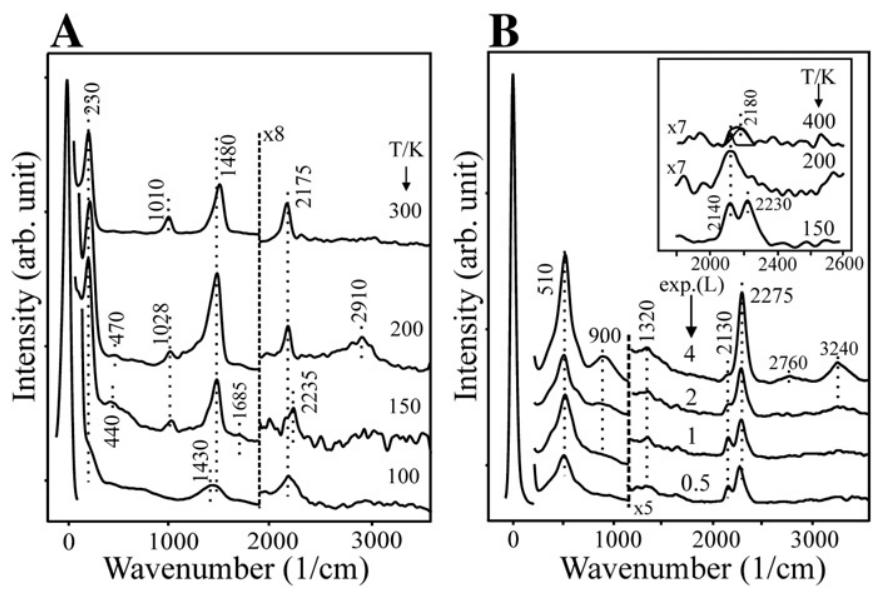

Fig. 3. Effects of preadsorbed oxygen $\left(\Theta_{O} \sim 0.3\right)(A)$ and $\mathrm{Ar}$ ion bombardment (B) on the HREEL spectra of HNCO on $\mathrm{Au}(111)$ at $\sim 100 \mathrm{~K}$. In the segment the effect of annealing is presented.

temperatures, we also observed HNCO desorption with Tp 230-210 K (Fig. 2A). We attribute this peak to HNCO molecules produced after recombination of $\mathrm{H}_{(\mathrm{a})}$ and $\mathrm{NCO}_{(\mathrm{a})}$ species. When we searched after reaction products, we detected weak signals of amu 28 and 12 at $\mathrm{T}_{\mathrm{p}} \sim 480 \mathrm{~K}$ (Fig. 2B), which we attribute to the release of $\mathrm{CO}$ and $\mathrm{N}_{2}$ formed in the decomposition of NCO bonded to $\mathrm{Au}$

$\mathrm{NCO}_{(\mathrm{a})}=\mathrm{CO}_{(\mathrm{g})}+\mathrm{N}_{(\mathrm{a})}$

$2 \mathrm{~N}_{(\mathrm{a})}=\mathrm{N}_{2(\mathrm{~g})}$

As CO does not remain adsorbed on clean $\mathrm{Au}(111)$ above $250 \mathrm{~K}$ [47], the above peak temperature indicates the stability of NCO on $\mathrm{Au}(111)$ surface. We may also assume that the $\mathrm{N}$ atoms formed in the process described by Eq. (2), also recombine after their production. We did not observe peak at $\mathrm{M}(42)$ due to the desorption of NCO. This is in harmony with the results obtained in previous papers.

These results confirm the assignment and the interpretation of FTIR spectra obtained following the $\mathrm{NO}+\mathrm{CO}$ reaction on supported Au catalysts [34,35]. Adsorption of $\mathrm{NO}+\mathrm{CO}$ gas mixture on $\mathrm{Au} / \mathrm{SiO}_{2}$ at $473-523 \mathrm{~K}$ produced an intense absorption band at $\sim 2190 \mathrm{~cm}^{-1}$, together with a weak band at $2305 \mathrm{~cm}^{-1}$. After longer reaction time and/or at higher temperature the $2190 \mathrm{~cm}^{-1}$ band attenuated and
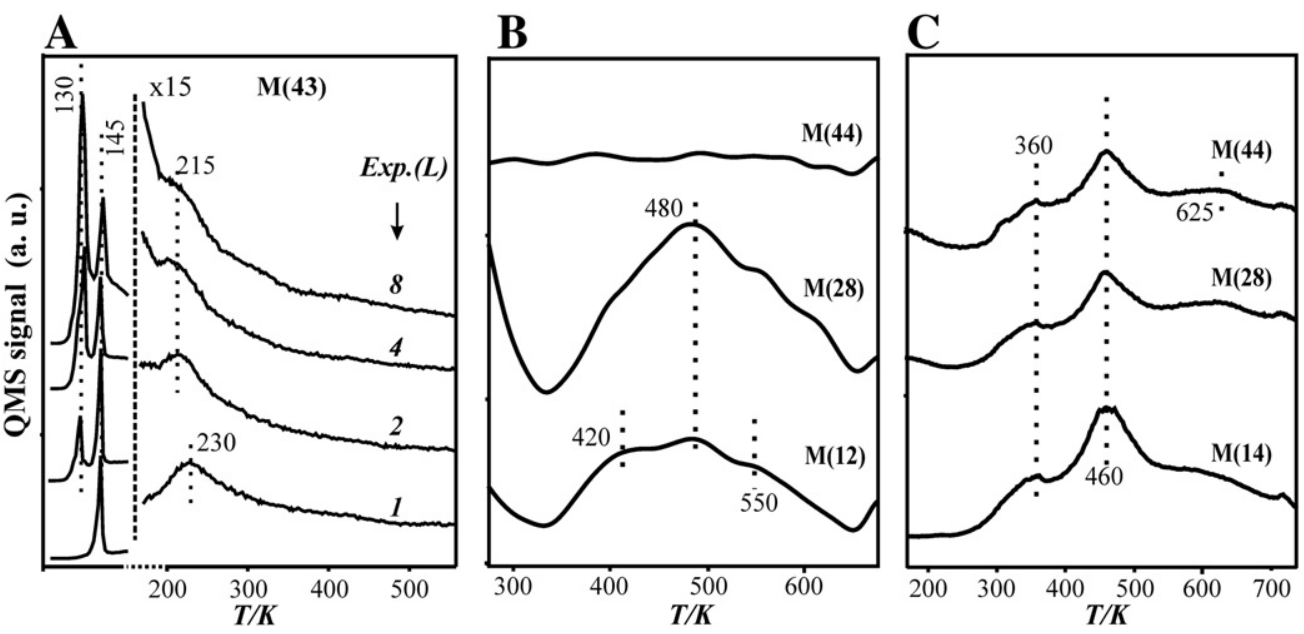

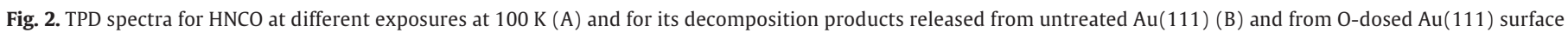
(C). $\mathrm{T}_{\mathrm{a}} \approx 110 \mathrm{~K}$. The approximate coverage of adsorbed $\mathrm{O}$ is $0.2-0.3$. 

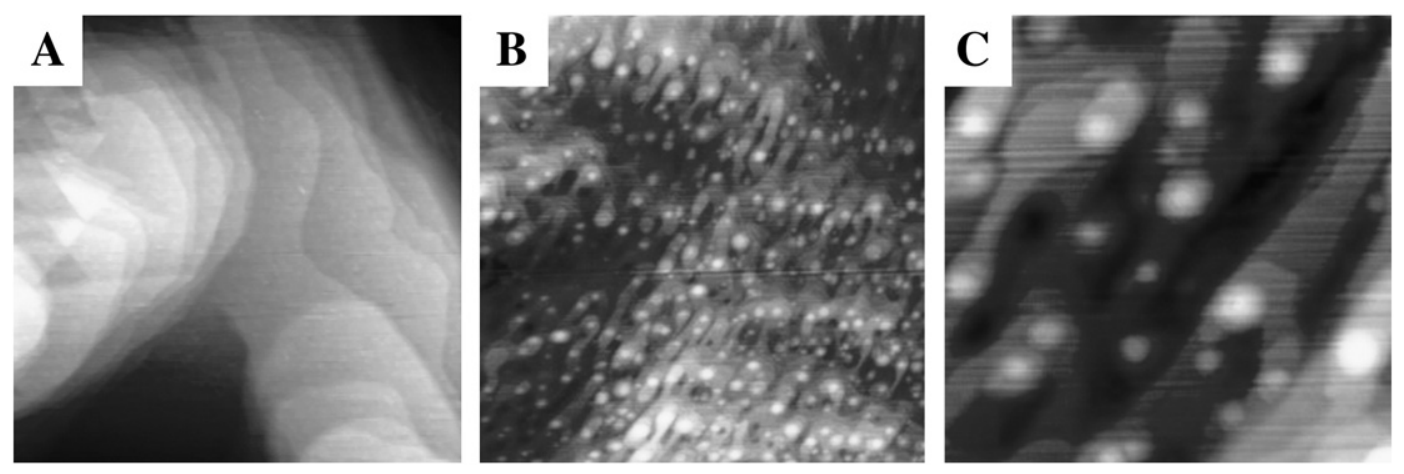

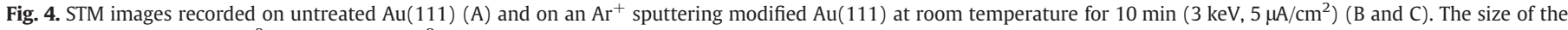
images: (A, B) $400 \times 400 \mathrm{~nm}^{2}$, (C) $100 \times 100 \mathrm{~nm}^{2}$. The STM images were recorded at a bias of $+1 \mathrm{~V}$ on the sample and an average tunneling current of app. $10 \mathrm{nA}$

disappeared. At the same time the band at $2305 \mathrm{~cm}^{-1}$ due to Si-NCO strengthened and finally dominated the spectra. This feature is in agreement with the results obtained following the dissociative adsorption of HNCO on supported Au catalyst [34,35]. On the Au/ $\mathrm{TiO}_{2}$ and $\mathrm{Au} / \mathrm{SiO}_{2}$ samples the absorption band at $2180-2190 \mathrm{~cm}^{-1}$ due to Au-NCO was present even at $523 \mathrm{~K}$.

\subsection{Oxygen-dosed $A u(111)$}

In the subsequent measurements we examined the adsorption of HNCO on $\mathrm{Au}(111)$ containing adsorbed $\mathrm{O}$ atoms. HREEL spectra are presented in Fig. 3A. The vibration loss at $2175 \mathrm{~cm}^{-1}$ due to NCO species already appeared at $100 \mathrm{~K}$, e.g. at considerably lower temperatures than on a clean $\mathrm{Au}(111)$ sample. This result clearly suggests that $\mathrm{O}$ atoms on $\mathrm{Au}(111)$ surface promote the dissociation of HNCO, very likely due to the formation of $\mathrm{OH}$ species

$\mathrm{HNCO}_{(\mathrm{g})}+\mathrm{O}_{(\mathrm{a})}=\mathrm{NCO}_{(\mathrm{a})}+\mathrm{OH}_{(\mathrm{a})}$

We could not find unambiguous evidences for the formation of $\mathrm{OH}_{(\mathrm{a})}$ on the HREEL spectra which possibly caused by the orientation of the hydroxyl species or by the very low surface concentration.

By means of TPD measurements we detected the evolution of $\mathrm{CO}_{2}$ with $\mathrm{T}_{\mathrm{p}}=360$ and $460 \mathrm{~K}$ in addition to that of $\mathrm{CO}$ and $\mathrm{N}_{2}$ (Fig. 2C). This suggests that NCO reacted with preadsorbed $\mathrm{O}$

$\mathrm{NCO}_{(\mathrm{a})}+\mathrm{O}_{(\mathrm{a})}=\mathrm{CO}_{2(\mathrm{~g})}+1 / 2 \mathrm{~N}_{2(\mathrm{~g})}$

yielding $\mathrm{CO}_{2}$. We can explain the attendance of this double desorption peak possibly by the presence of different kind of adsorption sites available on the reconstructed $\mathrm{Au}(111)$ surface. $\mathrm{As} \mathrm{CO}_{2}$ is not bonded to $\mathrm{Au}(111)$ surface above $200 \mathrm{~K}$ [48], its high $\mathrm{Tp}$ value for the evolution of $\mathrm{CO}_{2}$ indicates the reaction temperature of the oxidation process.

In addition to the above described effect it should be taken into account that the generation of atomic oxygen using electron-induced dissociation of $\mathrm{NO}_{2}$ induces restructuring of $\mathrm{Au}(111)$ herringbone structure. This is accompanied by the formation of small gold island and/or serrated step edge due to the release of gold atoms at the expense of herringbone elbow sites (dislocation sites) [42]. This feature can also contribute to the enhanced reactivity toward HNCO adsorption and dissociation. But this surface modification is much less than that caused by $\mathrm{Ar}^{+}$bombardment.

\subsection{Argon ion bombarded $A u(111)$}

The interaction of HNCO and its chemistry were also investigated on $\mathrm{Ar}$ ion bombarded $\mathrm{Au}(111)$ surface. First we examined the structural changes occurred on the $\mathrm{Au}(111)$ sample. In Fig. 4 we present scanning tunneling (STM) images recorded on a well ordered (annealed) and an $\mathrm{Ar}^{+}$bombardment modified $\mathrm{Au}(111)$ surface.
The intact surface exhibits characteristically large, atomically smooth terraces, with monatomic steps between the terraces (Fig. 4A). The corrugation (height difference between the highest and lowest points of the imaged area) was approximately $4-5 \mathrm{~nm}$ for an image size of $400 \times 400 \mathrm{~nm}^{2}$. This parameter does not vary significantly on the effect of an $\mathrm{Ar}^{+}$bombardment of $3 \mathrm{keV}$ ion energy and $5 \mu \mathrm{A} / \mathrm{cm}^{2}$ ion current density at room temperature for $10 \mathrm{~min}$ (Fig. 4B), however, the main characteristic of the original morphology changes dramatically. Instead of extended monoatomic terraces, parallel running hills with a periodicity of approximately $20 \mathrm{~nm}$ and individual dot-like features of $10-15 \mathrm{~nm}$ diameter can be seen everywhere. The small scale corrugation increases significantly, mainly due to the outrising dots which consist usually of 4-6 rising steps (Fig. 4C). This STM image of $100 \times 100 \mathrm{~nm}^{2}$ also shows parallel hills running in the diagonal direction of the region. The front line of this surface wave is probably perpendicular to the direction of the generating $\mathrm{Ar}^{+}$beam. As a conclusion, these STM measurements reveal that ion bombardment increased the density of steps significantly whereas the typical terrace width was considerably reduced, especially at the side walls of the pits and mounds. Interestingly, although the ion bombardment transformed the flat terraces into a net of pits and mounds, the determining features are still (111) terraces with a strongly reduced average lateral size. According to the quantitative analysis of several images taken on freshly sputtered surfaces, we concluded that the sputtering increased the density of Au atoms located at step edge sites by almost 2 orders of magnitude (up to $10^{14}$ step atoms $/ \mathrm{cm}^{2}$ ). It can obviously be assumed that this tendency is even more evident when the sputtering is performed deep below room temperature. It appears clearly that $\mathrm{Ar}$ ion bombardment increases significantly the density of steps on $\mathrm{Au}(111)$ surface, whereas the typical terrace width is considerably reduced. Note that annealing the etched sample at $500 \mathrm{~K}$ for $1-2 \mathrm{~min}$ leads a complete restoration of the original surface ordering.

Exposures of the etched $\mathrm{Au}(111)$ surface to $\mathrm{HNCO}$ at $100 \mathrm{~K}$ resulted qualitatively in the same spectral features as in the case of the untreated sample. The intensity of the loss at $2275 \mathrm{~cm}^{-1}$ (Fig. 3B) due to asymmetric stretching of molecularly bonded HNCO was, however, appreciably larger than that measured on an untreated surface at the same exposure. This can be attributed to the higher active surfaces area of the $\mathrm{Ar}^{+}$bombarded sample. A more important difference is that the loss feature at $2185 \mathrm{~cm}^{-1}$ observed on an unperturbed surface is missing. Instead, a new loss at $2130 \mathrm{~cm}^{-1}$ developed. Its intensity somewhat enhanced up to $150 \mathrm{~K}$, and attenuated at higher temperatures. On the basis of previous interpretation, we may assume that this peak belongs to NCO formed in the dissociation of adsorbed HNCO (Eq. (1)). Its appearance at $100 \mathrm{~K}$ can be attributed to the high concentration of the low coordinated atoms generated by the sputtering of $\mathrm{Au}(111)$ surface, which are significantly more active than the highly coordinated terrace atoms. The lower position of the NCO vibration is probably the result of different electronic structure of the new sites. An alternative explanation could be that this loss is not 
due to NCO, but rather due to $\mathrm{CN}$ species formed in the breaking of the $\mathrm{C}-\mathrm{O}$ bond in the $\mathrm{NCO}$

$\mathrm{NCO}_{(\mathrm{a})}=\mathrm{CN}_{(\mathrm{a})}+\mathrm{O}_{(\mathrm{a})}$

This new reaction channel was not observed before following the HNCO adsorption on any metal [14-23], but was recently reported to occur in the interaction of HNCO with Pt(111) [24]. The existence of this route was supported by the formation of $\mathrm{NO}$ on the initially oxygen-free surface, and by the release of HCN. In the present case, however, there was no sign of the presence of the loss at $2170-2180 \mathrm{~cm}^{-1}$ due to NCO, and we could not detect the desorption of either NO or HCN. Therefore we incline to think that the vibration at $2130 \mathrm{~cm}^{-1}$ is the asymmetric stretching of NCO formed in the dissociation of HNCO on the very active sites of the etched $\mathrm{Au}(111)$ surface.

\subsection{Comparison of the behavior of Au with that of Pt metals}

The results unambiguously show that NCO species exists on Au surface. The position of the asymmetric stretching of NCO agrees well with that determined on Pt metal surfaces (Table 1). The chemistry of NCO on Au(111) surface, however, basically differs from that observed on Pt, Pd, and Rh single crystals. In the latter cases, NCO was found to be a relatively unstable surface compound; it decomposes completely at 300-330 K [14,15,23-25]. In the present case it existed even at $430 \mathrm{~K}$. The possible reason is that there is no driving force for its decomposition as the binding energy for Au-CO and $\mathrm{Au}-\mathrm{N}$ is much smaller than that on $\mathrm{Pt}$ metals.

A consequence of the high stability of NCO on Au metal is that it could be present in low concentration even in the catalytic reduction of NO with $\mathrm{CO}$ at high temperature. In other words it can function as a surface intermediate, or poisons the active sites of the Au nanoparticles. The role of NCO is possibly determined by the nature of the support. In the case of alumina support, when the spillover of $\mathrm{NCO}$ from $\mathrm{Au}$ onto $\mathrm{Al}_{2} \mathrm{O}_{3}$ is fast, the Au-NCO complex plays less role in the $\mathrm{NO}-\mathrm{CO}$ reaction. In contrast applying silica as a support when the migration of NCO from Au onto $\mathrm{SiO}_{2}$ is very slow, its existence on the Au may influence the reaction. From this point of view it would be interesting to compare the catalytic activity of $\mathrm{Au} / \mathrm{Al}_{2} \mathrm{O}_{3}$ and $\mathrm{Au} / \mathrm{SiO}_{2}$ in the $\mathrm{NO}+\mathrm{CO}$ reaction. Experiments are in progress to examine these considerations.

\section{Conclusions}

(i) HNCO adsorbs molecularly on pure Au(111) surface at $\sim 100 \mathrm{~K}$ and undergoes dissociation to NCO and $\mathrm{H}$ around $150 \mathrm{~K}$. NCO species formed on Au surface is stable up to $\sim 430 \mathrm{~K}$, e.g. at much higher temperatures than on Pt metals.

(ii) The characteristic vibration of NCO species bonded to Au(111) is at $2180-2190 \mathrm{~cm}^{-1}$, which suggests that the absorption bands observed at higher wavenumbers for supported Au catalyst during the $\mathrm{NO}+\mathrm{CO}$ reaction are due to NCO bonded not to the Au, but rather to the oxidic supports.

(iii) Preadsorbed oxygen and bombardment of the Au(111) surface with $\mathrm{Ar}$ ions enhanced the amount of weakly adsorbed HNCO, and induced the formation of NCO complex even at $100 \mathrm{~K}$.

(iv) Scanning tunneling microscopic measurements revealed the appearance of a large number of steps on the $\mathrm{Ar}$ ion treated $\mathrm{Au}$ surface, which are probably responsible for the enhanced reactivity towards $\mathrm{HNCO}$ dissociation.

\section{Acknowledgments}

This work was supported by the grant OTKA under contract number K 81517 and K 69200.

\section{References}

[1] M.L. Unland, J. Phys. Chem. 77 (1973) 1952; M.L. Unland, J. Catal. 31 (1973) 459.

[2] J.W. London, A.T. Bell, J. Catal. 31 (1973) 96.

[3] F. Solymosi, J. Sárkány, React. Kinet. Catal. Lett. 3 (1975) 297.

[4] M.F. Brown, R.D. Gonzalez, J. Catal. 44 (1976) 477.

[5] A.A. Davydov, A.T. Bell, J. Catal. 49 (1977) 345.

[6] F. Solymosi, J. Kiss, J. Sárkány, Proceedings, 7th International Vacuum Congress and 3rd International Conference on Solid Surfaces, Vienna, 1977, p. 819.

[7] F. Solymosi, L. Völgyesi, J. Sárkány, J. Catal. 54 (1978) 336.

[8] F. Solymosi, J. Sárkány, Appl. Surf. Sci. 3 (1979) 68.

[9] F. Solymosi, T. Bánsági, J. Phys. Chem. 83 (1979) 552.

[10] J. Raskó, F. Solymosi, J. Catal. 71 (1981) 219.

[11] D. Lorimer, A.T. Bell, J. Catal. 59 (1979) 223.

[12] T. Bánsági, J. Raskó, F. Solymosi, Proceedings, International Symposium on Spillover of Adsorbed Species, Lyon, Elsevier, Amsterdam, 1983, p. 109.

[13] W.C. Hecker, A.T. Bell, J. Catal. 85 (1984) 389.

[14] R.J. Gorte, L.D. Schmidt, B.A. Sexton, J. Catal. 67 (1981) 387.

[15] J. Kiss, F. Solymosi, J. Catal. 179 (1998) 277.

[16] K.L. Kostov, P. Jacob, H. Rauscher, D. Menzel, J. Phys. Chem. 95 (1991) 7785

[17] K.L. Kostov, H. Rauscher, D. Menzel, Surf. Sci. 287/288 (1993) 283.

[18] J.H. Miners, A.M. Bradshaw, P. Gardner, Phys. Chem. Chem. Phys. 1 (1999) 4909.

[19] E. Ozensoy, C. Hess, D.W. Goodman, J. Am. Chem. Soc. 124 (2002) 8524.

[20] H. Celio, K. Mudalige, P. Mills, M. Trenary, Surf. Sci. 394 (1997) L168.

[21] C. Hess, D.W. Goodman, E. Ozensoy, J. Phys. Chem. B 107 (2003) 2759.

[22] C. Hess, E. Ozensoy, D.W. Goodman, J. Phys. Chem. B 108 (2004) 14181.

[23] R. Németh, J. Kiss, F. Solymosi, J. Phys. Chem. C 111 (2007) 1424.

[24] E. Herceg, J. Jones, K. Mudiyanselage, M. Trenary, Surf. Sci. 600 (2006) 4563.

[25] J.E. Jones, M. Trenary, J. Phys. Chem. C 112 (2008) 20443.

[26] F. Solymosi, A. Berkó, T.I. Tarnóczi, Appl. Surf. Sci. 18 (1984) 233.

[27] R.M. Ferullo, N.J. Castellani, J. Mol. Catal. A: Chem. 221 (2004) 155

[28] G.R. Garda, R.M. Ferullo, N.J. Castellani, Surf. Sci. 598 (2005) 57.

[29] P.G. Belelli, M.M. Branda, G.R. Garda, R.M. Ferullo, N.J. Castellani, Surf. Sci. 604 (2010) 442.

[30] P.G. Belelli, G.R. Garda, R.M. Ferullo, Surf. Sci. 605 (2011) 1202 and references therein.

[31] A. Uleda, M. Haruta, Gold Bull. 32 (1999) 3.

[32] J.Y. Lee, J. Schwank, J. Catal. 102 (1986) 207.

[33] M.A. Debeila, N.J. Coville, M.S. Scurrell, G.R. Hearne, Catal. Today 72 (2002) 79.

[34] F. Solymosi, T. Bánsági, T. Süli Zakar, Catal. Lett. 87 (2003) 7.

[35] F. Solymosi, T. Bánsági, T. Süli Zakar, Phys. Chem. Chem. Phys. 5 (2003) 4724

[36] W.L. Chan, E. Chason, J. Appl. Phys. 101 (2007) 121301 and references therein

[37] Z. Pászti, O. Hakkel, T. Keszthelyi, A. Berkó, N. Balázs, I. Bakó, L. Guczi, Langmuir 26 (2010) 16312.

[38] L. Savio, L. Vattuone, M. Rocca, Phys. Rev. B 67 (2003) 045406.

[39] O. Skibbe, D. Vogel, M. Binder, A. Pucci, T. Kravchuk, L. Vattuone, V. Venugopal, A. Kokalj, M. Rocca, J. Chem. Phys. 131 (2009) 024701.

[40] A. Politano, G. Chiarello, J. Phys. D: Appl. Phys. 43 (2010) 085302.

[41] J.V. Barth, H. Brune, G. Ertl, R. Behm, J. Phys. Rev. B 42 (1990) 9307.

[42] X. Deng, B.K. Min, A. Guloy, C.M. Friend, J. Am. Chem. Soc. 127 (2005) 9267

[43] J. Gong, B. Mullins, Acc. Chem. Res. 42 (2009) 1063 and references therein.

[44] S.A.C. Carabinerio, B.E. Nieuwenhuys, Gold Bull. 43 (2010) 252.

[45] F. Solymosi, J. Kiss, Surf. Sci. 104 (1981) 181.

[46] M. Surman, F. Solymosi, R.D. Diehl, P. Hofmann, D.A. King, Surf. Sci. 146 (1984) 135.

[47] W.-L. Yim, T. Nowitzki, M. Necke, H. Schnars, P. Nickut, J. Biener, M.M. Biener, V. Zielasek, K. Al-Shamery, T. Klüner, M. Bäumer, J. Phys. Chem. C 111 (2007) 445

[48] A.P. Farkas, F. Solymosi, J. Phys. Chem. C 113 (2009) 19930. 